\title{
Carfilzomib Regimen
}

National Cancer Institute

\section{Source}

National Cancer Institute. Carfilzomib Regimen. NCI Thesaurus. Code C160798.

A regimen consisting of carfilzomib that may be used in the treatment of relapsed or refractory plasma cell myeloma and in the treatment of Waldenstrom macroglobulinemia. 